\title{
Estimativa de Capacidade com a Técnica de Dispersão de Pacotes em Redes CDMA 1xEVDO e o Impacto da Degradação do Sinal
}

\author{
Adriel Bilharva da Silva e Luiz Nacamura Júnior
}

\begin{abstract}
Resumo-Este trabalho apresenta um estudo sobre o impacto da degradação do sinal na estimativa de capacidade de transmissão em redes de comunicações móveis CDMA 1xEVDO, utilizando a técnica de dispersão de pares de pacotes. Através de medidas práticas, foi investigado o comportamento das estimativas de capacidade em conexões 1xEVDO, em diferente condições de qualidade do canal de comunicação sem fio.
\end{abstract}

Palavras-Chave-Estimação de capacidade, dispersão de pacotes, canal de comunicação sem fio, CDMA 1xEVDO.

Abstract - This work shows an study about influency of signal degradation in capacity estimation using packet pair dispertion techniques over CDMA 1xEVDO mobile communication system. Through practical measurements, the behave of capacity estimation in 1xEVDO conections was examinated in different quality conditions of wireless channel.

Keywords-Capacity estimation, packet dispersion techniques, wireless channel, CDMA 1xEVDO.

\section{INTRODUÇÃO}

De encontro a crescente demanda por mobilidade no acesso à internet, surgiu a tecnologia de terceira geração da telefonia celular, chamada Evolution-Data Optimized (1xEVDO) [1], que utiliza-se da técnica de múltiplo acesso por divisão de código (CDMA). Atualmente presente em 49 países, esta tecnologia apresenta expressivo crescimento mundial, segundo levantamento [2], é utilizada por 83 operadoras com mais de 90 milhões de usuários. Evolução das tecnologias CDMA IS95(2G) e 1xRTT(2,5G), o 1xEVDO foi otimizado para o tráfego de dados, assim apresenta duas diferenças fundamentais em relação as versões anteriores. A primeira é o esquema de taxa de transmissão adaptativa, ajusta em função da relação sinal-ruído do canal (SNR) medido pelo usuário. A segunda é que os dados transmitidos no enlace direto são multiplexados no tempo. Desta forma, cada usuário ocupa a portadora por uma fração de tempo, determinada segundo um algoritmo de agendamento de envio de pacotes.

Assim como em redes com fio, saber qual é a menor taxa de transmissão de um caminho de rede, ou capacidade de contenção, pode auxiliar no funcionamento de vários aplicativos [3]. Por exemplo, aplicações "peer-to-peer" podem utilizar estas estimativas para escolher o melhor "peer". Serviços de mídia contínua utilizam a estimativa de capacidade para auxiliar no ajuste da taxa de transmissão do servidor para o cliente multimídia, como no caso do Windows Streaming Media, que

Adriel Bilharva da Silva e Luiz Nacamura Júnior, CPGEI, UTFPR, Curitiba, Paraná, Brasil, E-mails: adriel.silva@vivo.com.br, nacamura@utfpr.edu.br utiliza o método da dispersão de pares de pacotes para estimar a capacidade de contenção entre servidor e cliente [4], [5].

De uma forma geral, em redes sem fio as ferramentas de estimação de capacidade de transmissão existentes apresentam resultados menos precisos, pois elas foram originalmente desenvolvidas para redes com fio, sem prever as condições adversas encontradas no canal de comunicação sem fio [5]. Os trabalhos [5], [6] evidenciam as principais dificuldades encontradas com o uso da técnica de dispersão de pacotes para estimar a capacidade de contenção em redes sem fio. Neste tipo de rede, a probabilidade de erros no canal de comunicação é muito elevada, então mecanismos de retransmissão de frames implementados pelo Media Access Control (MAC) e Radio Link Protocol (RLP) são essenciais para evitar perda de pacotes. Por outro lado, estas retransmissões elevam a variância das medidas de dispersão dos pacotes, tornando o resultado inconsistente. Outra fonte de imprecisão apontada é a utilização de algoritmos de agendamento de envio de pacotes que não seguem a ordem First In First Out (FIFO), pois normalmente são implementados algoritmos que buscam a justiça na distribuição do tráfego, e não a ordem de chegada.

Para minimizar a imprecisão na estimativa de capacidade de contenção e aumentar a eficiência da técnica de dispersão de pacotes em redes celulares $1 \mathrm{xEVDO}$, é preciso realizar um estudo do comportamento desta técnica neste tipo de rede sem fio, e determinar as influências da degradação do sinal, e do tráfego concorrente na interface aérea e dos algoritmos de agendamento de pacotes.

Neste trabalho investigamos como a degradação do sinal na interface aérea pode influênciar no resultado da estimação de capacidade, baseada na técnica de dispersão de pares de pacotes. Para esta análise foram realizadas medidas práticas em variadas condições de cobertura no sistema celular 1xEVDO da operadora Vivo S.A., na cidade de Curitiba/PR. Estimouse a capacidade de contenção entre um computador equipado com um terminal de acesso 1xEVDO e um computador na Universidade Tecnológica Federal do Paraná (UTFPR). Neste caso, já havia um conhecimento prévio de que a capacidade de contenção do enlace direto seria definida pelo último enlace do caminho de rede, ou seja, a interface aérea entre o Access Network (AN) [1] e o Access Terminal (AT) [1].

A continuação deste artigo está organizada com segue. Na seção II apresentamos a técnica tradicional da dispersão de pacotes. Na seção III revisamos as principais características da interface aérea 1xEVDO. Na seção IV mostramos o ambiente dos testes e os resultados práticos das medidas realizadas. 
Finalmente, na seção $\mathrm{V}$ fazemos os comentários finais e sugestões de trabalhos futuros.

\section{TÉCNICA DE DISPERSÃO DE PACOTES}

A técnica de dispersão de pacotes [7] é um processo de medição ativa com a finalidade de estimar a capacidade de contenção de uma conexão fim-a-fim. A capacidade de contenção será igual à menor capacidade de transmissão dentre todos os enlaces que compõem um caminho de rede. Devese salientar que, no contexto deste trabalho, a capacidade está relacionada ao valor máximo de transmissão de dados por uma unidade de tempo, diferentemente de banda disponível, que é a máxima largura de banda ${ }^{1}$ livre para utilização. Na referência [3], Dovrolis apresenta um exemplo claro a cerca destas duas métricas, que por vezes são confundidas.

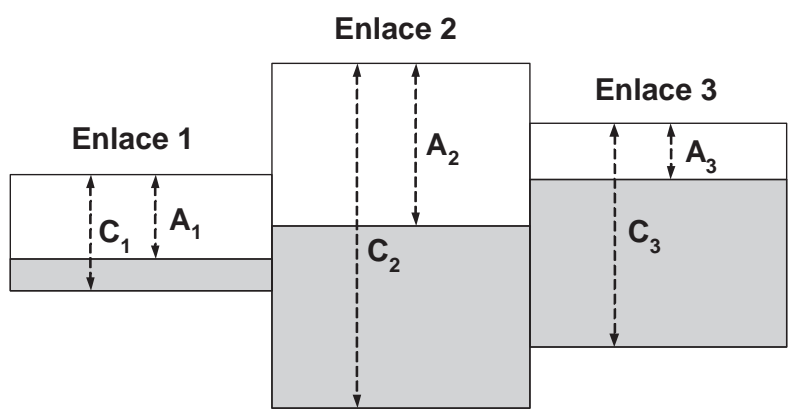

Fig. 1. Exemplo do modelo de tráfego de fluidos para uma rede com três enlaces de diferentes capacidades [3].

A Fig. 1 representa um caminho de rede específico composto por três enlaces, sob o modelo de tráfego de fluidos, onde a largura de cada um dos tubos equivale à capacidade relativa do enlace. A área sombreada corresponde à parte da capacidade utilizada em cada enlace, enquanto a área não sombreada corresponde à reserva ainda não utilizada. $\mathrm{O}$ enlace 1 com a menor capacidade $C_{1}$ determina a capacidade de contenção deste caminho de rede, ao passo que a banda disponível do mesmo caminho de rede é determinada pelo enlace 3 , que possui a menor banda disponível $A_{3}$. Isto evidencia que nem sempre estas métricas serão determinadas pelo mesmo enlace.

Como pode ser visto na Fig. 2, a técnica de dispersão de pares de pacotes consiste no envio de dois pacotes de sondagem de tamanhos iguais, de um emissor para um receptor, com intervalo de saída próximo de zero. O espaçamento entre os pacotes é mantido até que eles passem por um enlace com taxa de transmissão menor que a do emissor. Após atravessarem todos enlaces do caminho de rede, estes pacotes apresentarão dispersão equivalente ao tempo gasto em sua transmissão no enlace de menor capacidade, determinando assim a capacidade de contenção.

\footnotetext{
${ }^{1}$ Neste contexto, o termo largura de banda está relacionado à quantidade de dados que um enlace consegue entregar por unidade de tempo, diferente do contexto de sistemas de comunicação, onde largura de banda está relacionada ao espectro de freqüência utilizado para transmissão de sinais eletromagnéti$\cos$.
}

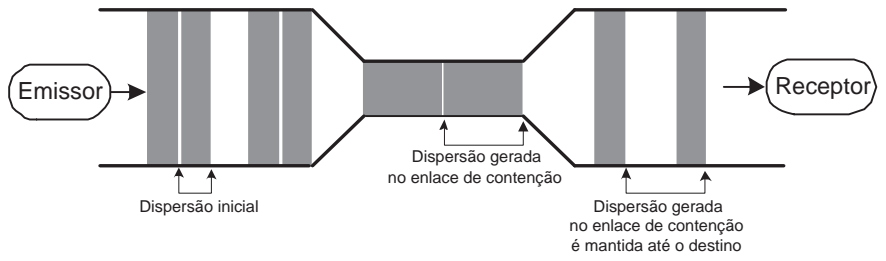

Fig. 2. Ilustração do comportamento do pacotes de sondagem após passarem pelo enlace de contenção [8].

A dispersão de um par de pacotes pode ser descrita mais formalmente, considerando um caminho de rede $P$ composto por $H$ enlaces com capacidades $C_{i}$, e taxa de transmissão do emissor $C_{0}$, assim $P=\left\{C_{0}, C_{1}, C_{2}, \ldots C_{H}\right\}$. A capacidade de contenção do caminho $P$ será definida pelo enlace com a menor capacidade, e pode ser escrita por:

$$
C=\min _{i=0 \cdots H} C_{i}
$$

Sendo a dispersão $\delta$ medida entre os pacotes de sondagem de comprimento $L$, a capacidade de contenção $C$ é definida por:

$$
C=\frac{L}{\delta}
$$

Considerando a inexistência de tráfego concorrente, a dispersão de apenas um par de pacotes já seria suficiente para o cálculo da capacidade de contenção. Entretanto nem sempre esta suposição é verdadeira, já que a presença de tráfego pode interferir na estimativa desta métrica de duas formas. A primeira é quando pacotes de tráfego concorrente são transmitidos entre os pares de pacotes de sondagem, aumentando a dispersão entre os pacotes, conseqüentemente causando uma subestimação de capacidade. A segunda é quando os pacotes de sondagem já que passaram pelo enlace de menor capacidade, devido ao tráfego, enfrentam filas nos roteadores subseqüentes do caminho, causando assim buferização dos pacotes de sondagem, reduzindo a dispersão, gerando uma superestimação de capacidade.

A referência [7] mostra, por meio de simulações e testes práticos, que o tamanho do pacote também pode influenciar no resultado da estimativa. Quando maior os pacotes de sondagem, maior a probabilidade de roteadores colocarem pacotes de tráfego entre eles, causando subestimação de capacidade. Por outro lado, pacotes de sondagem pequenos são mais vulneráveis a filas nos roteadores, podendo gerar superestimação de capacidade. Este trabalho também mostra que uma boa alternativa para amenizar os efeitos do tráfego concorrente na estimativa desta métrica é a utilização de pares de pacotes de sondagem com tamanho variável.

\section{REDE CDMA $1 \times E$ VDO}

Para analisar o comportamento da técnica da dispersão de pacotes na rede CDMA $1 \times E V D O$, é preciso saber como o tráfego de dados é processado neste tipo de rede. Inicialmente, os pacotes de dados entrantes na rede 1xEVDO são encapsulados com Protocolo Ponto-a-Ponto (PPP) e compactados para um transporte mais eficiente no canal de comunicação sem 
fio. Numa segunda etapa estes pacotes são segmentados em frames RLP, que é um protocolo onde executa-se um esquema local de retransmissão na interface aérea, com a finalidade de ocultar perdas de pacotes das camadas superiores como TCP [9].

A Fig. 3 mostra a forma como o tráfego é transportado no enlace direto, dividido em streams paralelos. O stream 0 é utilizado para sinalização, os outros três streams RLP levam os dados, e podem ser utilizados para suportar aplicações com diferentes níveis de Qualidade de Serviço (QoS) [1]. A camada inferior MAC é responsável por multiplexar os frames RLP, fazendo um novo encapsulamentodos em frames MAC, de acordo com as necessidades da camada física, comum a todos usuários.

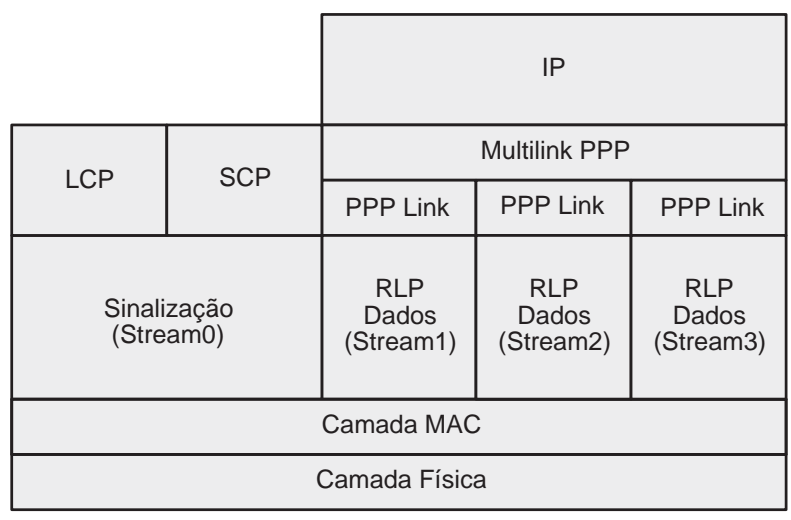

Fig. 3. Pilha de protocolos simplificada 1xEVDO [10].

No 1xEVDO, ao contrário das versões anteriores do CDMA, a interface aérea do enlace direto faz a separação de seus usuários no tempo. Assim os frames são multiplexados e transmitidos com potência constante e igual para todos, porém com taxa de transferência de dados e quantidade de slots diferentes para cada usuário. No caso de não haver frames de dados na fila, a única transmissão é a rajada de piloto (Pilot Burst). O diagrama de transmissão do enlace direto é ilustrado na Fig. 4.

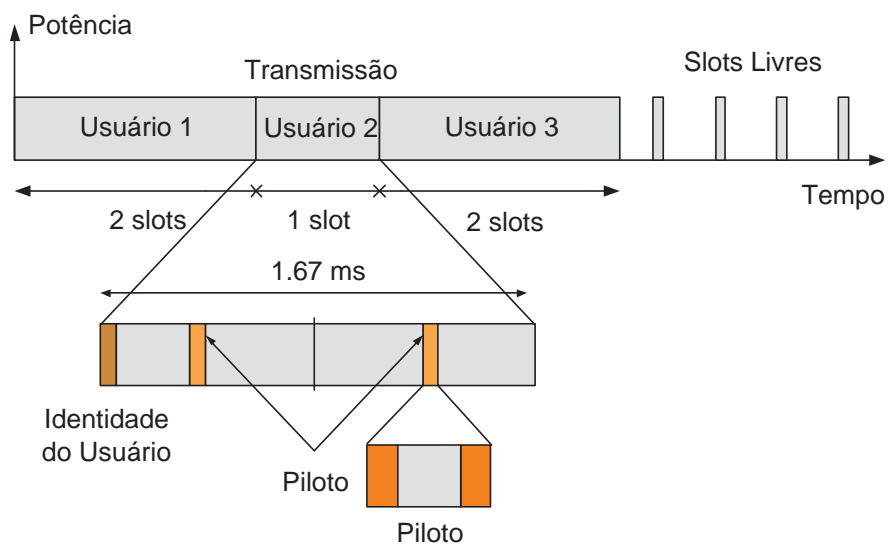

Fig. 4. Diagrama de transmissão do enlace direto [10].

A transmissão do piloto permite que o AT realize uma predição do desvanecimento do canal através de medidas presentes e passadas. Dentre outros parâmentros é medida a Energia por chip sobre a densidade espectral de potência de ruído (Ec/No) de todos os multipercursos, obtendo-se rapidamente uma predição efetiva da razão sinal-ruído do canal (SNR). Conhecendo as condições do canal, o AT determina a máxima taxa de transferência de dados que ele pode solicitar ao AN com um desempenho satisfatório. Tipicamente com taxa de erro de pacote (PER) de 1 a $2 \%$ [10], [11]. A Tabela I apresenta os valores de $S N R$ requeridos para transferência de dados com $1 \%$ de PER.

TABELA I

SNR ADMITINDO 1\% DE PER [10].

\begin{tabular}{|c|c|}
\hline Taxa de Transmissão (kbps) & SNR (dB) \\
\hline 38.4 & -12.5 \\
\hline 76.8 & -9.5 \\
\hline 102.6 & -8.5 \\
\hline 153.6 & -6.5 \\
\hline 204.8 & -5.7 \\
\hline 307.2 & -4.0 \\
\hline 614.4 & -1.0 \\
\hline 921.6 & 1.3 \\
\hline 1228.8 & 3.0 \\
\hline 1843.2 & 7.2 \\
\hline 2457.6 & 9.5 \\
\hline
\end{tabular}

Assim cada AT estima as condições do canal e solicita a taxa de transferência para os próximos pacotes a serem recebidos por ele. As solicitações de todos ATs são atendidas por meio de um algoritmo, implementado pelo MAC na camada de enlace do AN, que agenda o envio dos pacotes para os respectivos ATs de acordo com sua prioridade. O algoritmo de agendamento deve buscar imparcialidade entre usuários e o maior desempenho para o sistema. Neste trabalho todos os testes foram realizados com a utilização do algoritmo Proportional Fairness. Este algoritmo estabelece prioridade de atendimento em função da relação entre a taxa de transmissão solicitada e a quantidade de dados enviados para cada usuário [12], [13].

\section{EXPERIMENTAÇ̃̃o PRÁTICA}

A análise da influência da degradação do sinal foi feita baseada nos resultados das estimativas de capacidade realizadas na rede comercial 1xEVDO da operadora Vivo, na cidade de Curitiba/PR. Pares de pacotes foram enviados a partir de um computador emissor, localizado na Universidade Tecnológica Federal do Paraná (UTFPR), para outro computador receptor conectado à internet por um terminal de acesso 1xEVDO kyocera kpc650. A Fig.5 apresenta a topologia da rede onde foram realizados os experimentos.

Neste caminho de rede onde foram realizados os testes, conhecidamente a capacidade de contenção é determinada pelo último salto, entre AN e AT, pois este é o enlace com menor capacidade de transmissão. Nesta topologia proposta, não existem roteadores posteriores ao enlace com menor capacidade, conseqüentemente não existe a possibilidade de ocorrer superestimação de capacidade provocada por filas. Desta maneira, a dispersão dos pacotes de sondagem era causada pela interface aérea 1xEVDO, sendo possível analisar o impacto da degradação do sinal nas estimativas de capacidade. 


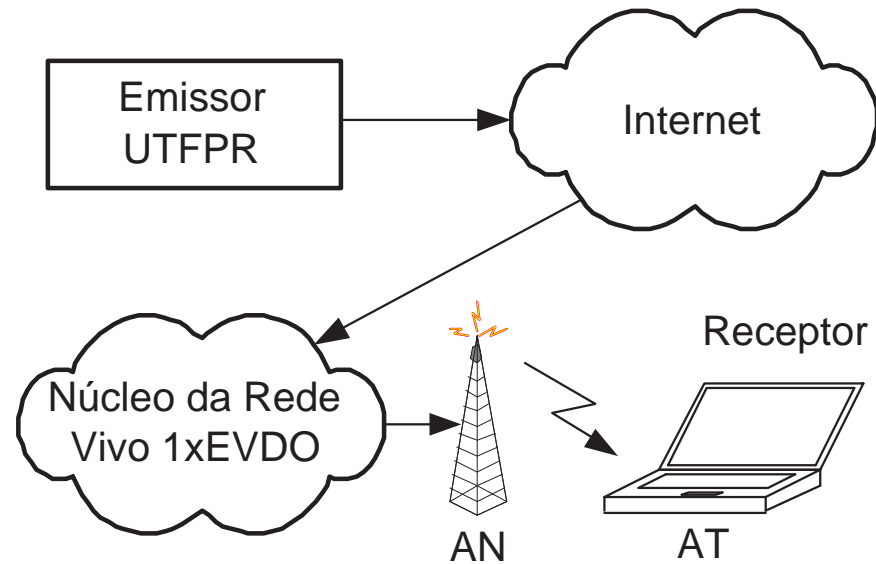

Fig. 5. Topologia da rede experimental.

Durante a realização dos testes, os pacotes de sondagem deixavam o computador emissor na UTFPR e eram transportados pela internet como pacotes IP, até alcançarem a rede 1xEVDO, onde eram encapsulados em pacotes PPP e posteriormente segmentados em frames RLP. Estes frames eram levados até o AN e convertidos em frames compatíveis com a camada física, para serem enviados com a taxa de transmissão previamente solicitada pelo AT, seguindo as prioridades do algoritmo de agendamento de envio de pacotes configurado no AN. A Fig. 6 apresenta a arquitetura das camadas lógicas, considerando a topologia da rede experimental.

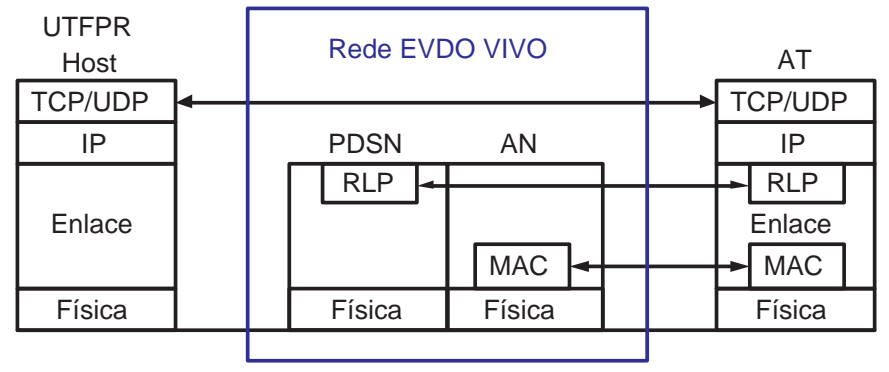

Fig. 6. Camadas da interface aérea 1xEVDO.

Para este trabalho foi desenvolvida uma ferramenta baseada no Pathrate [7], que é um software com a finalidade de estimar a capacidade de contenção. Foi utilizada a técnica de dispersão de pares de pacotes, com um computador emissor enviando mil pares de pacotes UDP de sondagem, com o comprimento $L$ variando de 600 até 1440 Bytes. Na camada de transporte do computador receptor, era medida dispersão $\delta$ entre os pares de pacotes UDP.

Os resultados das estimativas de capacidade, baseadas em (2), são apresentados em um histograma com resolução de $25 \mathrm{kbps}$, para avaliar estatisticamente a função de densidade de probabilidade (fdp) das estimativas de capacidade. O histograma resultante das medidas gera uma distribuição multimodal [14], na qual a moda global [14], que é o intervalo com a maior intensidade, representa a capacidade de contenção do caminho de rede.
A realização dos experimentos foi feita em um ambiente controlado, onde a ocupação da interface aérea 1xEVDO foi monitorada com um analisador Agilent E7495B [15], que media a ocupação da rede em função da quantidade de Slots livres detectados no enlace direto, similar ao apresentado na Fig. 4. Todos os testes foram realizados com no máximo $30 \%$ de ocupação, evitando assim que o tráfego concorrente na interface aérea impactasse nas estimativas de capacidade.

Foram realizados testes em várias condições de cobertura, onde percebemos que as estimativas de capacidade apresentavam dois padrões de comportamentos, determinados pelos níveis de $S N R$ estimado pelo AT. Sendo níveis de $S N R$ iguais ou superiores a $-1 \mathrm{~dB}$ considerado cenários de sinal bom e inferiores a $-1 \mathrm{~dB}$ considerado cenário de sinal ruim. Os resultados obtidos nestes dois cenários são apresentados a seguir.

\section{A. Cenário de Sinal Bom}

Neste cenário a capacidade foi facilmente estimada pelo histograma de medidas, que com pequena variância apresentou apenas duas modas, sendo uma delas com intensidade desprezível, ficando muito claro que a capacidade era de $500 \mathrm{kbps}$, como pode ser visto em um dos resultados apresentado na Fig. 7. Este resultado é similar ao apresentado no trabalho [16], onde foi realizada estimação de capacidade de contenção de uma conexão 1xEVDO realizado na rede da operadora Sprint, na cidade de Worcester, Massachusetts.

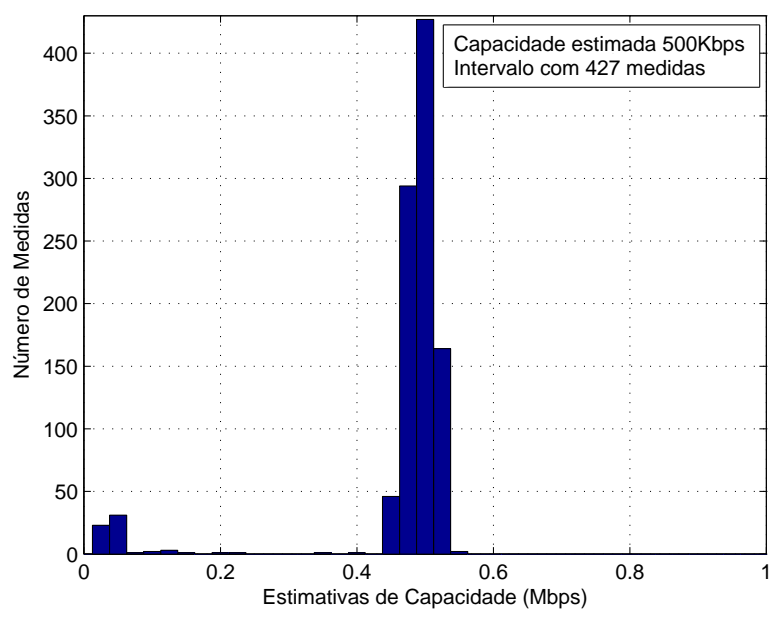

Fig. 7. Histograma das estimativas de capacidade com cenário de sinal bom.

Porém, diferentemente do trabalho [16], salientamos que a capacidade estimada aqui, não é a máxima capacidade que um conexão 1xEVDO pode alcançar, mas sim a máxima capacidade que uma aplicação pode obter utilizando apenas um stream RLP de dados. Testes práticos realizados com o software CAIT [17], ferramenta de análise da interface áerea CDMA, mostram que a taxa de transmissão máxima só é obtida com a utilização dos três streams RLP de dados, e com bons níveis de $S N R$ medidos pelo AT sob análise. Desta forma, utilizando apenas um stream RLP, mesmo quando o AT 
solicita taxa de transmissão de dados na camada física entre $614.4 \mathrm{kbps}$ e $2457.6 \mathrm{kbps}$, o resultado estimado continua sendo próximo de $500 k b p s$.

Outra constatação importante, é que a variância nas estimativas de capacidade é inversamente proporcional ao tamanho dos pacotes de sondagem. A Fig. 8 mostra o mesmo resultado apresentado na Fig. 7, porém plotado em ordem cronológica de acontecimento. A resolução da medida de dispersão dos pacotes em nossa ferramenta era $6 \mu \mathrm{s}$, porém a maneira como os pacotes são fragmentados e transmitidos pela rede 1xEVDO, fazia com que percebessemos apenas variações em saltos de $1 \mathrm{em} 1 \mathrm{~ms}$, assim a resolução percebida passou a ser de $1 \mathrm{~ms}$, gerando então maior imprecisão em pacotes pequenos. Fica evidenciado que as estimativas de capacidade convergem para o valor de 500kbps a medida em que o pacote de sondagem é incrementado pelo nosso programa.

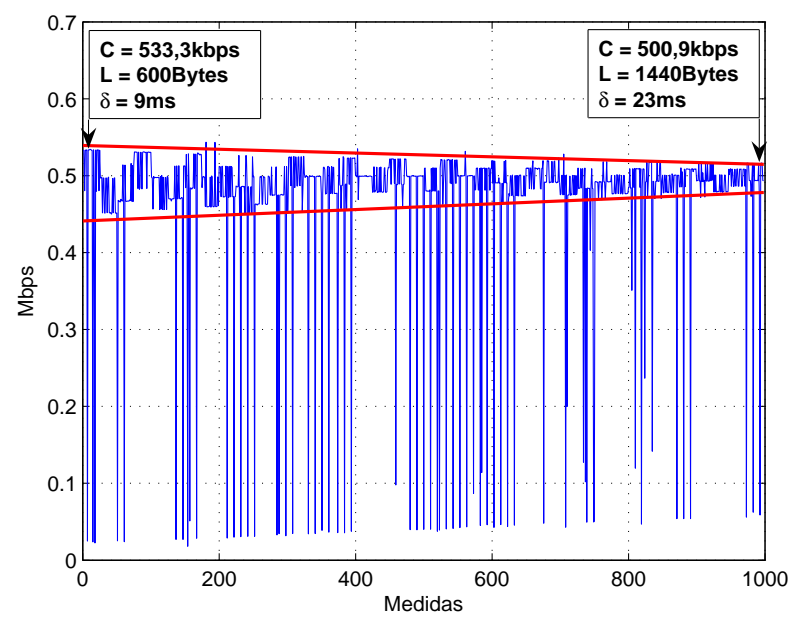

Fig. 8. Estimativas de capacidade na ordem cronológica de acontecimento no cenário de sinal bom.

\section{B. Cenário de Sinal Ruim}

Neste cenário, o canal de comunicação sem fio apresenta muita variação nos níveis de $S N R$, dificultando bastante a estimativa de capacidade, pois o AT solicita taxas de transmissão baixas e variadas. Com a diminuição do $S N R$, outro problema que surge é o aumento da probabilidade de erros no canal de comunicação, fazendo com que atuem os mecanismos de retransmissão de frames, implementados pelo MAC e RLP, essenciais para evitar perda de pacotes, porém eles elevam a variância das medidas de dispersão dos pacotes tornando o resultado inconsistente. A Fig. 9 mostra uma estimativa realizada neste cenário, no qual o histograma apresenta uma distribuição multimodal, onde existe um grupo de modas de intensidades desprezíveis centradas em $25 k b p s, 75 k b p s$ e $500 \mathrm{kbps}$, uma moda centrada em 300kbps com intensidade 75 estimativas, com valor muito proximo da moda global centrada em $175 \mathrm{Kbps}$ com 83 estimativas. Esta proximidade na intensidade das modas torna difícil a definição precisa da capacidade de contenção.

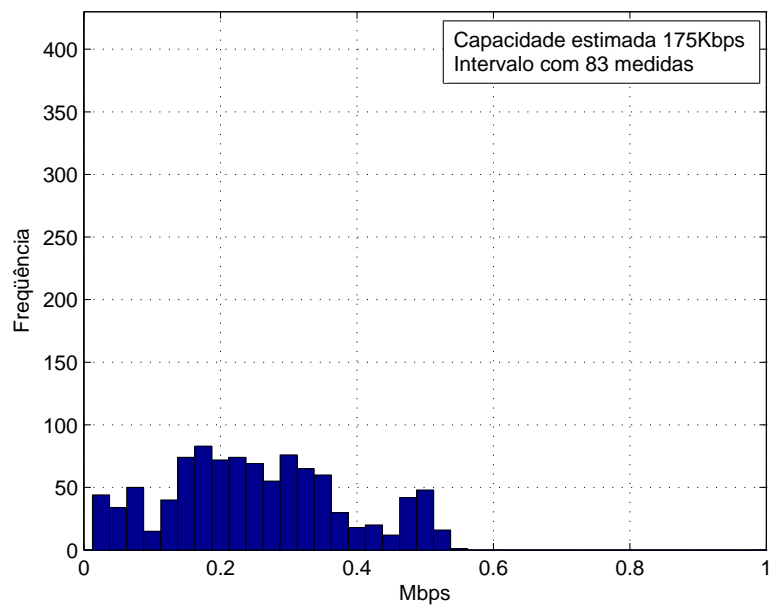

Fig. 9. Histograma das estimativas de capacidade com cenário de sinal ruim.

A duração do processo de estimação da capacidade com envio de mil pares de pacotes de sondagem é de aproximadamente 20 minutos, durante este periodo as condições do canal variam muito, não sendo possível traçar uma linha de tendência para as estimativas de capacidade, similar ao realizado no cenário de sinal bom. A Fig. 10 mostra o mesmo resultado apresentado na Fig. 9, porém plotado em ordem cronológica de acontecimento, assim é possível perceber claramente as variações no canal de comunicação sem fio ao longo do tempo.

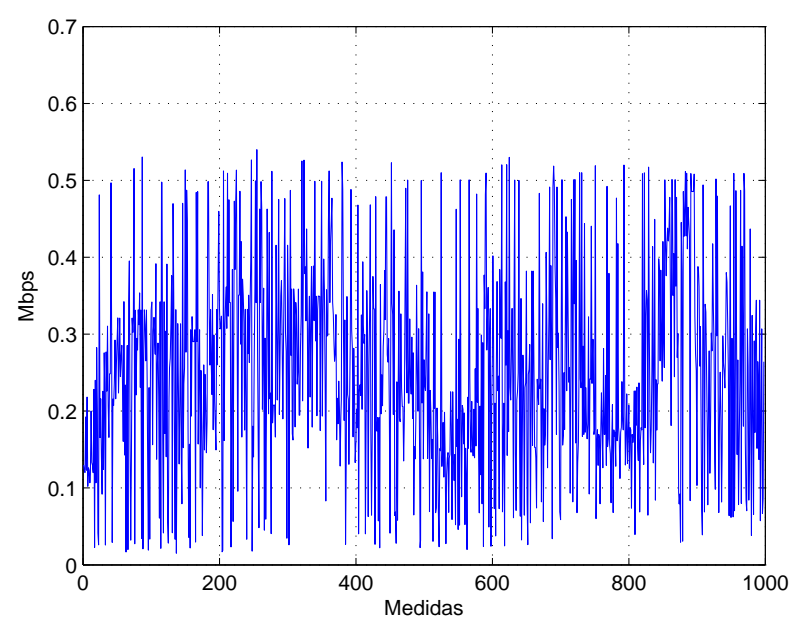

Fig. 10. Estimativas de capacidade na ordem cronológica de acontecimento no cenário de sinal ruim.

\section{Conclusões}

Trabalhos anteriores [5], [6] demonstram que as ferramentas de estimação de capacidade de transmissão existentes, de uma maneira geral desenvolvidas para redes com fio, apresentam resultados menos precisos em redes sem fio. 
Assim como os trabalhos [5], [6] indicam que a degradação do sinal aumenta a probabilidade de erros no canal de comunicação sem fio, gerando estimativas de capacidade menos precisas, neste trabalho pudemos comprovar através de testes práticos na rede 1xEVDO, que em condições de baixo $S N R$ a presença dos mecanismos de retransmissão frames MAC e RLP, aliada a variação na taxa de transmissão solicitada pelo AT, são fatores que tornam, nestas condições, a estimativa de capacidade menos precisas neste tipo de rede.

$\mathrm{Na}$ situações em que o canal de comunicação sem fio apresentava boa qualidade de $S N R$, obtivemos resultados semelhantes aos apresentados no estudo [16], porém salientamos que a capacidade estimada no nosso trabalho não representa a máxima capacidade que um conexão $1 \mathrm{xEVDO}$ pode alcançar, mas sim a máxima capacidade que uma aplicação pode obter utilizando apenas um stream RLP de dados. Assim, mesmo quando o AT solicita taxa de transmissão de dados na camada física entre $614.4 \mathrm{kbps}$ e $2457.6 \mathrm{kbps}$, o resultado estimado continua sendo próximo de $500 \mathrm{kbps}$, pois estamos utilizando apenas um stream RLP nas estimativas de capacidade.

Por fim, constatamos que o tamanho do pacote de sondagem é inversamente proporcional a variância nas estimativas de capacidade em redes 1xEVDO.

Como trabalho futuro, pretendemos estudar o desempenho da técnica de dispersão de pacotes para estimar a capacidade de contenção em sistemas de comunicações móveis CDMA 1xEVDO, abordando a influência do tráfego concorrente na interface aérea.

\section{AgRAdecimentos}

A operadora Vivo S.A., por permitir a realização dos testes em seu sistema de comunicações móveis CDMA 1xEVDO, na cidade de Curitiba/PR.

Ao aluno da graduação Anderson Vermonde, por auxiliar no desenvolvimento da ferramenta de estimação de capacidade.

\section{REFERÊNCIAS}

[1] TIA/EIA/IS-856 "CDMA2000, High Rate Packet Data Air Interface Specification"

[2] CDMA Development Group, "Quick Marhttp://www.cdg.org/technology/cdma_technology/cdma_stats.asp.

[3] R. Prasad, C. Dovrolis, M. Murray, K. Claffy, "Bandwidth estimation: metrics, measurement techniques, and tools", IEEE Network, Dec. 2003, pp. 27-35.

[4] A. Rocha, R. Leão, E. de Souza e Silva, "An End-to-End Technique to Estimate the Transmission Rate of an IEEE 802.11 WLAN", Proceedings of the IEEE, 1-6, 2007.

[5] M. Li, M. Claypool, R. Kinicki, "Packet Dispersion in IEEE 802.11 Wireless Networks", Proceedings of Local Computer Networks, pp.71229, Nov. 2006

[6] K. Lakshminarayanan, V. N. Padmanabhan, J. Padhye, "Bandwidth estimation in broadband access networks", Proceedings of IMC 2004, Taormina, Sicily, Italy, Oct. 2004.

[7] C. Dovrolis, P. Ramanathan, and D. Moore, "Packet-dispersion techniques and a capacity-estimation methodology", IEEE/ACM Transactions, Vol 12, no.6, 963-977, 2004.

[8] V. Jacobson,"Congestion Avoidance and Control", Proc. ACM SIGCOMM, Sept. 1988, pp. 314-29.

[9] M. Andress, L. Zhang, "A CDMA Data Measurement and Analysis Tool", 4th International Symposium on Modeling and Optimization in Mobile, pp. 1-8, April 2006.
[10] P. Bender, et al., "CDMA/HDR: A bandwidth-eficient high speed wireless data service for nomadic users", IEEE communication magazine, july. 2000, pp. 70-77.

[11] Qi Bi, Stan Vitebsky, "Performance Analysis of 3G-1X EVDO High Data Rate System", WCNC2002. IEEE 2002.

[12] K. Kim, H Kim, Y Han "A proportionally fair scheduling algorithm with QoS and priority in 1xEV-DO", Personal, Indoor and Mobile Radio Communications, pp 15-18, Sept 2002.

[13] J. M. Holtzman, "Asymptotic analysis of proportional fair algorithm", Personal, Indoor and Mobile Radio Communications, pp 33-37, sept. 2001.

[14] C. Dovrolis, P. Ramanathan, and D. Moore, "What do Packet Dispersion Techniques Measure?", Proc. IEEE INFOCOM, Apr. 2001, pp. 905-14.

[15] E7495B Base Station Test Tool Product Overview, http:www.agilent.com

[16] M. Claypool, R. Kinicki, M. Li, "Characterization by Measurement of a CDMA 1x EVDO", WiConf06, Aug. 2006.

[17] QCTest CDMA Air Interface Test(CAIT), http://www.qualcomm.com. 